\title{
DEMONSTRAÇÕES CONSOLIDADAS PRÓ-FORMA: IMPORTÂNCIA AVALIADA EM UM CASO REAL
}

\author{
Itamar Miranda Machado
}

Professor das Faculdades Ibmec - MG

E-mail: itamarm@uol.com.br

\section{Ariovaldo dos Santos}

Professor Livre-Docente do Depto. de Contabilidade e Atuária - FEA-USP

E-mail: arisanto@usp.br

\section{RESUMO}

Este estudo aborda a consolidação das demonstrações contábeis quando ocorre aquisição do controle de empresas, enfatizando a questão da comparabilidade das demonstrações entre o período da aquisição, o anterior e o posterior a ele. Quando uma sociedade é inserida, pela primeira vez, no consolidado da adquirente, este fato pode gerar uma perda de comparabilidade, pois, no ano de aquisição do controle, o balanço patrimonial é consolidado integralmente, mas a demonstração do resultado é consolidada apenas a partir da data da compra. Portanto, pode haver um prejuízo à análise comparativa, pois, no ano anterior, não houve consolidação, uma vez que a controlada não fazia parte do grupo econômico da adquirente e, no ano posterior à aquisição, consolidam-se os doze meses das contas de resultado.

O estudo tem como objetivo apresentar uma alternativa para o resgate da comparabilidade entre as demonstrações consolidadas em períodos em que haja aquisição de controle de empresas ou reestruturação societária. Tal comparabilidade pode ser conseguida através de demonstrações consolidadas pró-forma.

Complementando o estudo, apresenta-se pesquisa realizada junto a profissionais ligados aos mercados financeiro e de capitais, com a finalidade de avaliar suas opiniões quanto à publicação das demonstrações consolidadas pró-forma, quando fatos relevantes, como aquisição de controle e reestruturações societárias, ocorrem.

Palavras-chave: Demonstrações Contábeis Consolidadas; Investimentos Permanentes; Comparabilidade; Pró-forma; Controle de Empresas.

\section{ABSTRACT}

This study deals with the consolidation of financial statements upon the acquisition of company control, emphasizing the comparability of statements at the time of acquisition, in the preceding and in the subsequent period. When a subsidiary is inserted for the first time in the consolidated balance of the holding company, this fact may lead to decreased comparability because, in the year of control acquisition, the balance sheet is fully consolidated, but the income statement is only consolidated from the acquisition date onwards. Therefore, the comparative analysis may be impaired since, in the previous year, there was no consolidation, since the subsidiary was not part of the economic group of the holding company while, in the next period, twelve months are consolidated in the accounts.

The study aims to present an alternative to recover comparability between consolidated statements in control acquisition or business restructuring periods. This comparison can be achieved through pro forma consolidated statements.

As a complement, we present a research carried out among financial and capital market professionals in order to evaluate their opinions about the publication of pro forma consolidated statements when relevant facts occur, such as control acquisition and business restructuring.

Keywords: Consolidated Financial Statements; Permanent Investments; Comparability; Pro forma; Control of companies.

Recebido em $15.01 .03 \cdot$ Aceito em $23.10 .03 \cdot 2^{\mathrm{a}}$ Versão aceita em 17.12.03 


\section{INTRODUÇÃO}

Um dos grandes objetivos da Contabilidade é o de oferecer informações a respeito da vida das empresas. A melhoria da qualidade dessas informações tem sido motivo de muitos estudos e pesquisas dos órgãos nacionais e internacionais, assim como de professores, estudantes e profissionais da área contábil.

Nesse sentido, a forma de avaliar os investimentos permanentes em outras sociedades tem merecido, ao longo dos anos, bastante atenção, pois as empresas, além das atividades relacionadas à produção e venda de bens e serviços, também participam de outras empresas. Regra geral, essa participação tem como objetivo a otimização de seu resultado global.

Outro motivo para a expansão dos investimentos em outras sociedades é a oportunidade de diversificação das atividades. O Brasil passou, nos últimos anos, por um período bastante intenso de privatizações. Empresas dos mais variados segmentos adquiriram o controle de empresas de telecomunicações, saneamento, energia, concessões de rodovias e ferrovias, etc.. Godoy \& Santos ${ }^{1}$, no artigo intitulado Push-Down Accounting, mencionam que:

No Brasil, o crescimento do número de fusões e aquisições de empresas tem sido incentivado por diversas iniciativas, sendo uma das mais importantes a criação do Programa Nacional de Desestatização (PND), gerido pelo Banco Nacional de Desenvolvimento Econômico e Social (BNDES). O PND brasileiro privatizou grande número de empresas estatais, oferecendo oportunidades de expansão não só para as empresas locais, mas também para as empresas ainda não instaladas no país, interessadas em expansão geográfica dentro de um mercado potencial.

A KPMG Brasil² divulgou um estudo feito por ela, intitulado Fusões \& Aquisições, em que mostra o crescimento das aquisições no Brasil da década de 90 para cá. O tópico "O mundo aterrissou no Brasil" destaca que:

O Brasil virou alvo do capital externo na década de 90. Diversas nacionalidades decidiram entrar em terras brasileiras investindo em setores em expansão. A liderança da década ficou com os Estados Unidos. De acordo com a pesquisa da KPMG Brasil, os americanos totalizaram 457 transações nos últimos dez anos. O segundo lugar ficou com a França, com 111 negócios. Em seguida aparecem o Reino Único (69), Alemanha (60).

Segundo a pesquisa, na década de 90 houve um crescimento acumulado de $134 \%$ no número de fusões e aquisições em relação à década anterior, sendo que $61 \%$ das operações envolveram investimentos estrangeiros. A pesquisa mostra que, entre 1994 e 2001, ocorreram 2.440 transações deste tipo. Cinco setores foram os responsáveis por $36 \%$ delas, destacando-se o setor de alimentos, bebidas e fumos. Os gráficos 1 e 2 , apresentados a seguir, mostram o volume de transações no período e os cinco setores mais representativos.

Em função desse alto número de transações envolvendo aquisições e fusões de empresas, torna-se importante verificar como os investimentos de caráter permanente em outras sociedades devem ser reconhecidos na investidora, e também como demonstrar a situação econômica e financeira de entidades que, embora juridicamente separadas, representam uma única entidade econômica. Através das demonstrações consolidadas é possível avaliar um grupo econômico. 


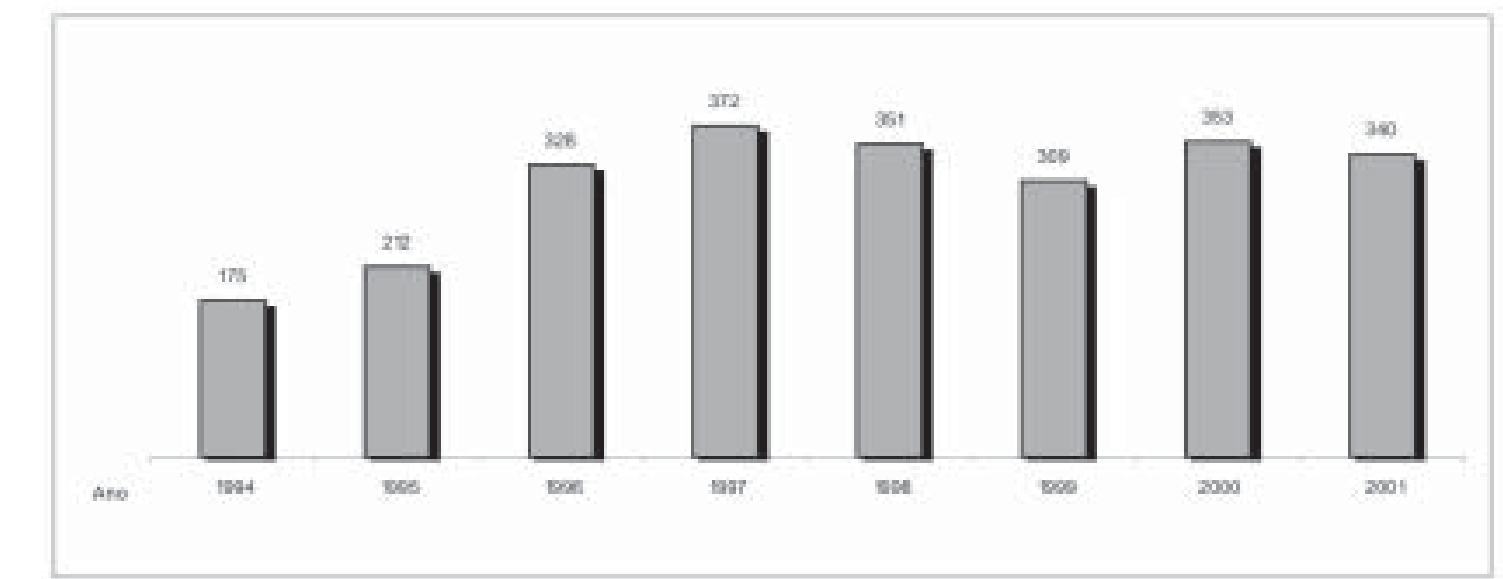

Fonte: KPMG Corporate Finance

\section{Gráfico 1 - Fusões e Aquisições no Brasil}

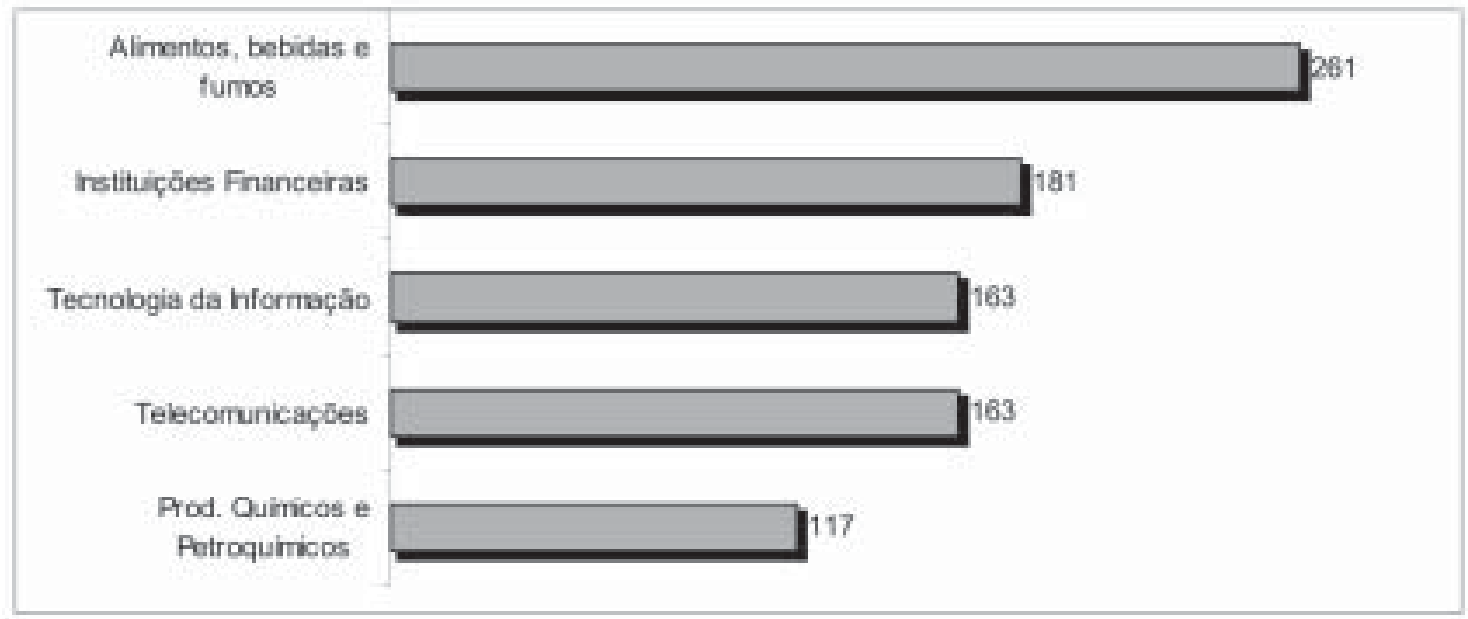

Fonte: KPMG Corporate Finance

Gráfico 2 - Cinco setores que lideraram as Fusões e Aquisições no Brasil no período - 1994 a 2001

\section{CONSOLIDAÇÃO DAS DEMONSTRAÇÕES CONTÁBEIS}

Consolidar consiste em agrupar as demonstrações contábeis das empresas controladas às demonstrações da controladora. Segundo a FIPECAFI ${ }^{3}$, o objetivo da consolidação é apresentar aos leitores, principalmente acionistas e credores, os resultados das operações e a posição financeira da sociedade controladora e suas controladas, como se o grupo fosse uma única empresa que tivesse uma ou mais filiais ou divisões. Isso permite uma visão mais geral e abrangente e melhor compreensão, do que inúmeros balanços isolados de cada empresa.

Esse tipo de demonstração é utilizado, nos Estados Unidos há cerca de um século. Em outros países iniciou-se bem mais tarde, aparecendo na legislação inglesa apenas em 1947, na alemã em 1965, no Japão em 1976 e na francesa em 1985.

Em inúmeros países não há obrigatoriedade de consolidação nem normatização sobre o assunto.

${ }^{3}$ FIPECAFI - USP. 
Assim, pode-se afirmar que, no Brasil, houve uma evolução nesse sentido. A esse respeito, Martins ${ }^{4}$ menciona que:

é de se notar que em inúmeros lugares

a consolidação é compulsória sempre que se possui uma controlada. No Brasil isso hoje é exigido pela CVM às companhias abertas. Em outros países, por outro lado, pode-se dizer que há inclusive atraso em relação ao Brasil.

Segundo Standerski ${ }^{5}$, no Brasil, esse assunto começou a ser normatizado na década de 1970 através da circular $n . .9179$ de 11.05.1972, expedida pelo Banco Central. A primeira empresa brasileira a publicar demonstrações consolidadas, de acordo com essa circular, foi a Petrobrás em 1975, referente ao exercício de 1974; no ano seguinte, foi seguida pelo Grupo Forja e pelo Grupo Real.

A obrigatoriedade de consolidação das demonstrações contábeis no Brasil foi introduzida, de forma ampla, pela Lei n 6.404 de 15 de dezembro de 1976, cujos artigos 249 e 250 destacam esse tema. A Comissão de Valores Mobiliários - CVM, autorizada por lei, pode e tem expedido normas a respeito desse assunto. O processo de regulamentação pela CVM iniciou-se pela Instrução n.․ 15, de 1980. Posteriormente, outras instruções foram emitidas, sendo que a de $n . \stackrel{0}{247}$, de março de 1996, é a mais recente (embora tenha sofrido pequenas alterações) ${ }^{6}$ e apresenta algumas inovações como, por exemplo, a consolidação proporcional.

Além da exigência de consolidação para as companhias abertas, no Brasil também, é exigido que as companhias de capital fechado, desde que constituam grupo de sociedades na forma do Capítulo XXI da Lei ํㅜ 6.404/ 76, elaborem demonstrações contábeis consolidadas.

Segundo Martins ${ }^{7}$, inicialmente a consolidação era feita com foco no controle, ou seja, nas empresas, em que havia a relação controladora-controlada, ou empresas sob controle comum. Posteriormente, surgiu a consolidação proporcional em função do crescente número de joint ventures, - em que existem investimentos com controle compartilhado, conforme afirma:
Nos países em que se processa há tantos anos a consolidação de balanços, desenvolveu-se, inicialmente, a regra básica de que só se consolidam demonstrações de controladora e controlada(s), ou de empresas sob controle comum. Mas sempre permanecendo o conceito de que só pode haver consolidação plena de balanços e de resultados quando há efetivamente a figura do controle. Depois, evolui-se para a figura do controle compartilhado (joint ventures).

Por último, chegou-se ao método de equivalência patrimonial, também chamado de one line consolidation, que surgiu para refletir, em uma única linha, a parcela do lucro ou prejuízo da investida que cabe à investidora, ou seja, é uma forma simplificada de se reconhecer os resultados das investidas - controladas, coligada e equiparadas - na controladora. Martins $^{8}$ menciona que a consolidação "nasceu" primeiro que a equivalência patrimonial.

Aqui também vale destacar a diferença que se deve fazer entre controle e propriedade, e o exemplo da legislação brasileira pode ser utilizado para exemplificar isso. Em 1976, quando a Lei № 6.404 foi aprovada, no artigo 15, parágrafo 2ํㅡㄹ estava previsto que o número de ações preferenciais sem direito a voto não poderia ultrapassar 2/3 (dois terços) do total das ações emitidas; isso significa dizer que as ações com direito a voto deveriam ser de no mínimo 1/3 (um terço). No limite extremo, apenas para exemplificação, se um acionista possuísse $50 \%$ mais uma das ações com direito a voto, admitindo-se que o total das ações emitidas tivesse respeitado aqueles limites legais, esse acionista seria o "controlador" da empresa, mas teria a propriedade de apenas $16,67 \%$ do total das ações. Por outro lado, um segundo acionista, que possuísse o restante das ações ordinárias e todo o conjunto das ações preferenciais seria o "proprietário" de $83,33 \%$ da empresa, mas não exerceria o controle. A partir da Lei ํㅜ 10.303, de 31 de outubro de 2001, o parágrafo $2^{\circ}$, do artigo

\footnotetext{
${ }^{4}$ MARTINS, Eliseu.

${ }^{5}$ STANDERSKI, Wlademiro.

${ }^{6}$ Alterada pela Instrução n ${ }^{\circ} 269 / 97$ que modificou o art. 23 e pela 285/98 que modificou o art. 14.

${ }^{7}$ op. cit. p. 1 .

${ }^{8}$ op. cit. p.1.
} 
15, determinou que o número de ações preferenciais, sem direito a voto, não pode ultrapassar $50 \%$ (cinqüenta por cento) do total das ações emitidas.

\section{1 - Método de Equivalência Patrimonial}

Esse método consiste em reconhecer os efeitos da variação do patrimônio líquido de cada coligada, equiparada e controlada no exercício social em que ocorre, independentemente de sua realização financeira. Este reconhecimento é proporcional ao percentual de participação da investidora no capital de cada investida. A Instrução $n . \stackrel{0}{247 / 96}$ da CVM, em seu artigo 50, determina que esse método deve ser aplicado nas seguintes situações:

I- O investimento em cada controlada, $e$

II- O investimento relevante em cada coligada e/ou sua equiparada, quando a investidora tenha influência na administração ou quando a porcentagem de participação, direta ou indireta da investidora representar $20 \%$ (vinte por cento) ou mais do capital social da coligada.

A determinação da relevância dos investimentos é feita pela relação percentual entre o Valor Contábil dos Investimentos - $\mathrm{VCI}$ no ativo da investidora e o valor do patrimônio líquido da própria investidora, ambos na data do balanço de encerramento. Considera-se relevante quando esta relação (VCI/PL) em cada coligada ou controlada for igual ou superior a $10 \%$, ou quando, no conjunto (todas as coligadas e controladas), for igual ou superior a $15 \%$. O cálculo do $\mathrm{VCl}$ se dá pela seguinte equação: valor do investimento + ágio não amortizado - deságio não amortizado + créditos de quaisquer natureza contra as coligadas e controladas (com exceção daqueles gerados pela própria atividade operacional).

A influência na administração é caracterizada pelo poder de participar nas decisões e políticas financeiras e operacionais da investida, sem que haja o controle.

\section{2 - Técnicas de Consolidação}

É necessário que haja uniformidade entre as práticas contábeis da controladora e das controladas, assim como uma adequação do período contábil, ou seja, não deve haver defasagem de data de encerramento do exercício social das empresas consolidadas, embora a legislação brasileira permita uma diferença de até 60 dias. No entanto, se fatos relevantes ocorrerem nesse período, faz-se necessário seu reconhecimento, ainda que extra-contábil.

O artigo 250 da Lei ํㅜ 6.404/76, determina que das demonstrações financeiras consolidadas deverão ser excluídas: participações de uma sociedade em outra; saldos de quaisquer contas entre as sociedades; as parcelas dos resultados do exercício, dos lucros ou prejuízos acumulados e do custo dos estoques ou do ativo permanente que corresponderem a resultados, ainda não realizados, de negócios entre as sociedades.

\section{3 - Participações Minoritárias}

Quando a controladora não possui $100 \%$ do capital social da controlada, significa que parte das quotas ou ações pertencem a outras pessoas. Esses outros sócios/acionistas podem ser pessoas físicas ou jurídicas e são denominados de minoritários ou não controladores.

Ao elaborar as demonstrações consolidadas, a controladora, mesmo tendo participação inferior a $100 \%$, deverá consolidar o valor integral de cada conta, pois o objeto da consolidação é o controle e não a propriedade. A controladora não tem a propriedade integral, mas tem o controle integral. Por isso, deverá consolidar $100 \%$ de todas as contas do ativo, do passivo e da demonstração do resultado. A legislação brasileira estabelece que a participação minoritária deve ser destacada em grupo isolado no balanço consolidado, imediatamente antes do patrimônio líquido, bem como em uma conta específica na Demonstração do Resultado do Exercício - DRE.

\section{CARACTERIZAÇÃO DO PROBLEMA}

Um dos grandes objetivos da Contabilidade é o de fornecer informações úteis para orientar o processo decisório nas organizações. Essas informações devem apresentar os impactos econômico-financeiros e até mesmo os sociais, decorrentes das transações realizadas no período, de forma que os usuários, principalmente os investidores e os credores, possam avaliar os reflexos de tais transações. A aquisição do controle de empresas durante 
o exercício social é uma operação relevante que poderá alterar substancialmente as demonstrações consolidadas.

No Brasil, as demonstrações são publicadas de forma comparativa, ou seja, publicam-se as do exercício social atual com as do ano anterior. Isso possibilita a análise das contas no sentido de que se possa inferir sobre as tendências futuras. Ocorre que, quando se adquire o controle de uma empresa, no primeiro ano da consolidação as contas de resultado da sociedade adquirida são consideradas apenas da data da aquisição até o encerramento do exercício social. No ano seguinte, consolidamse os doze meses destas contas. Então, surge a questão: como comparar demonstrações consolidadas se no ano anterior não havia a sociedade recém-adquirida, se no ano da aquisição consolidou-se apenas parte do resultado, e se, no seguinte a ela, consolidaram-se os doze meses? Há, portanto, uma perda de comparabilidade entre esses três exercícios sociais, o que pode prejudicar a análise feita pelos usuários.

Mais à frente, no item 4.2, quando se trata da consolidação da demonstração do resultado do exercício, outros subsídios são adicionados para uma meIhor análise e compreensão das dificuldades que poderão ser encontradas quando se comparam demonstrações consolidadas que tenham quantidades de meses diferentes.

\section{A CONSOLIDAÇÃO NO EXERCÍCIO SOCIAL DA AQUISIÇÃO DO CONTROLE}

A aquisição do controle de empresas ocorre, evidentemente, ao longo dos exercícios sociais. As empresas não esperam o primeiro dia do ano para fazer seus investimentos. Assim, no período em que ocorre a aquisição do controle de empresas, alguns cuidados devem ser tomados ao se efetuar a consolidação, conforme apresentado a seguir.

\section{1 - Consolidação do Balanço}

O balanço terá tratamento normal, ou seja, consolidam-se os valores linha a linha, porque ao adquirir o controle de uma entidade, há que se demonstrar o total dos ativos e passivos que estão sob controle comum na data da consolidação.

\section{2 - Consolidação da DRE}

As contas de resultado são um ponto que merece maior atenção quando ocorrem aquisições e vendas de empresas controladas, uma vez que a consolidação da demonstração do resultado deverá conter as contas da controladora durante todo o exercício social. No entanto, as da controlada devem se referir somente ao período compreendido entre a data da aquisição do controle e a data da consolidação, pois somente os resultados deste período é que foram controlados pela empresa adquirente, uma vez que os resultados anteriores à data da aquisição fizeram parte do patrimônio líquido adquirido. Da mesma forma, quando ocorrer a venda, essas contas serão consolidadas do início do exercício até a data da alienação da controlada.

\section{3 - Consolidação da DOAR}

A consolidação da DOAR deve ser feita a partir das demais demonstrações (Balanço e DRE) consolidadas e não das Demonstrações de Origens e Aplicações de Recursos individuais. Quando ocorrem aquisições durante $o$ ano essa necessidade se acentua, pois utilizando-se as demonstrações individuais problemas surgirão como, por exemplo: na consolidação da DRE, considera-se o resultado da controlada apenas após a data de aquisição; portanto, a soma dos resultados individuais constantes na DOAR de cada uma das empresas é diferente do resultado consolidado.

Os itens que fazem parte do ajuste ao lucro, como depreciação, amortização, despesas e receitas financeiras de longo prazo, etc., seguirão o mesmo critério do resultado, ou seja, serão considerados apenas os valores ocorridos após a data da aquisição.

\section{4 - Considerações gerais}

A DMPL não sofre influências nesse aspecto, uma vez que o patrimônio líquido da controlada, via de regra, é eliminado na consolidação.

Um aspecto importante é a necessidade de elaboração das demonstrações contábeis da empresa controlada na data da aquisição. Com isso, é possível determinar se houve ágio/deságio na operação, pela comparação entre o valor pago e o valor 
patrimonial das ações, e também separar o resultado anterior à aquisição e o posterior a ela, já que somente este último será consolidado.

\section{A IMPORTÂNCIA DA ANÁLISE COMPARATIVA ENTRE OS PERÍODOS}

A análise comparativa apresenta a evolução do patrimônio, das receitas e das despesas de uma entidade, ao longo dos períodos. Esta comparação se dá através da análise horizontal, também chamada análise de tendências, uma vez que possibilita inferir sobre as tendências futuras. É importante considerar que o ocorrido nos últimos períodos não necessariamente voltará a acontecer no futuro. No entanto, se fatos anormais ou extraordinários não ocorrerem, a possibilidade de uma evolução relativamente semeIhante à dos anos anteriores é grande.

Mello ${ }^{9}$, fazendo analogias, menciona que: um balanço, considerado isoladamente, é como que uma fotografia da situação de uma empresa. Por muito bem que seja tirada, a ponto de conter em si uma verdadeira noção de vida e dinamismo, nunca é, nem pode ser, mais do que uma secção, um corte, diga-se, da evolução da empresa em dado instante. Nada revela quanto à evolução que conduziu aos números dados e só deficientemente pode servir de base à previsão do futuro. Se em vez de uma única fotografia, fosse possível dispor-se de uma série destas, tiradas em instantes sucessivos, obter-se-ia pela comparação de cada uma com a seguinte uma visão de seqüência, de sentido de marcha, permitindo indução quanto ao futuro, pelo menos com relativa segurança, e é justamente a previsão do futuro que mais interessa ao analista, quer a análise seja preliminar para concessão de crédito ou colocação de capitais quer tenha fins puramente administrativos.
Myer ${ }^{10}$ faz importantes observações sobre o balanço comparativo, citando que: Enquanto o balanço simples enfatiza $o$ estado, o comparativo enfatiza a mudança (...) Embora o balanço seja uma demonstração útil, o balanço comparativo é ainda mais útil, já que ele contém não só os dados dos balanços individuais como também os dados que podem ser usados para estudar as tendências da empresa. As informações a respeito das tendências que indiquem a direção que tomam as atividades de uma determinada empresa geralmente são mais úteis ao analista do que o valor estrutural do ativo e passivo.

A demonstração do resultado apresenta uma revisão das atividades operacionais do negócio. O balanço comparativo dá o efeito das operações sobre o ativo e passivo. Dessa maneira, o balanço comparativo se constitui em um elo que liga o balanço à demonstração do resultado.

Os autores citados mencionam que a análise evolutiva do passado contribui para determinar a tendência da empresa no futuro. Myer faz importantes considerações sobre a correlação que há entre a demonstração do resultado e a variação do balanço entre dois períodos, ou seja, qual foi o benefício que o uso dos itens patrimoniais geraram naquele intervalo de tempo.

Em função da relevância da análise comparativa, a legislação brasileira determina que as demonstrações sejam publicadas de forma comparativa, ou seja, publica-se o exercício atual com o imediatamente anterior, para possibilitar que os usuários possam fazer suas análises de tendências.

\section{1 - Demonstrações Comparativas Pró-forma}

Delaney et al. ${ }^{11}$ definem "pró-forma" como "evidenciação requerida dos números computados, assumindo que determinados eventos tenham ocorrido",

\footnotetext{
${ }^{9}$ MELLO, Carlos E.S.S.

${ }^{10}$ MYER. John Nicholas.

${ }^{11}$ DELANEY, Patrick R. et al.
} 
ou seja, é uma maneira de refletir, nas demonstrações comparativas dos exercícios anteriores, fatos relevantes que ocorreram no presente, a fim de possibilitar a comparabilidade das demonstrações ao longo dos diversos períodos contábeis. Os autores mencionam, entre os fatos relevantes que justificam a elaboração do pró-forma, a "compra de um negócio". Portanto, a perda de comparabilidade nas demonstrações, quando ocorre a aquisição do controle de empresas, pode ser resgatada pela elaboração das demonstrações consolidadas pró-forma, como se o controle já existisse desde o início do exercício social anterior ao da aquisição do investimento.

\subsection{1 - Limitações das demonstrações consolidadas pró-forma}

Nas demonstrações consolidadas pró-forma do exercício anterior, somam-se as contas patrimoniais e as de resultado de entidades que, naquele ano, estavam sob controles distintos, ferindo, portanto, um dos principais objetivos das demonstrações consolidadas, que é apresentar, de forma conjunta, a situação econômico-financeira das empresas sob o mesmo controle. Dessa forma, quando se adquire o controle de uma empresa e se elaboram as demonstrações consolidadas pró-forma, incorporando às demonstrações do período anterior os ativos que não eram controlados pelo atual controlador, não há como afirmar se o lucro (ou prejuízo) daquele exercício seria exatamente o apresentado na demonstração de resultado consolidada, caso as duas entidades (controladora + controlada) já estivessem sob o mesmo controle.

Exemplificando: admita-se que, no ano anterior, a controladora apresentava um ativo total líquido de $\$$ 1.000 e obteve lucro de $\$ 100$ e que a atual controlada com um ativo total líquido de $\$ 500$ tivesse obtido um prejuízo de \$30; isso não significa, necessariamente, que o ativo total consolidado de $\$ 1.500$ tenha gerado um benefício líquido de $\$ 70$, pois se o ativo da empresa cujo controle fora recém-adquirido estivesse controlado, desde o exercício anterior, pelos atuais controladores, os resultados poderiam ter sido completamente diferentes.
Assim, o resultado consolidado pró-forma do exercício anterior não deve ser analisado como potencial de benefícios gerados pelos ativos consolidados, mas simplesmente como a soma dos resultados da controladora e da nova controlada, com a finalidade de demonstrar qual a variação do resultado de um período para o outro.

Portanto, a publicação das demonstrações consolidadas pró-forma não substitui as demonstrações elaboradas de acordo com a legislação, sendo elas apresentadas apenas como informações complementares, com a finalidade de facilitar o entendimento dos leitores, quando fatos relevantes como reestruturações societárias ou aquisições do controle de empresas acontecem. Tais demonstrações poderão ser úteis na análise comparativa das contas.

\subsection{2 - Pesquisa de campo sobre as demonstrações pró-forma}

Foi realizada pesquisa durante os meses de março e abril de 2002, com a finalidade de se saber a opinião de profissionais ligados aos mercados financeiro e de capitais sobre os assuntos tratados neste estudo, principalmente no que diz respeito às demonstrações consolidadas e à publicação das informações pró-forma. Esta pesquisa também teve o objetivo de testar se o procedimento adotado pela Andrade Gutierrez - $\mathrm{AG}^{12}$, no estudo de caso que está apresentado neste artigo, de publicar suas demonstrações consolidadas pró-forma, contribuiu para o entendimento dos analistas.

O método utilizado para compor a amostra foi o não probabilístico, sendo utilizada a amostragem intencional. Martins ${ }^{13}$ define esse tipo de amostragem da seguinte forma: de acordo com determinado critério, é escolhido intencionalmente um grupo de elementos que irão compor a amostra. O investigador se dirige intencionalmente a grupos de elementos dos quais deseja saber a opinião.

A amostra foi composta de 20 profissionais de 15 entidades, localizadas nas cidades de Belo Horizonte, Rio de Janeiro e São Paulo. Os profissionais são diretores, gerentes e analistas de crédito e de mercado e, por motivos variados, tiveram acesso

\footnotetext{
${ }^{12}$ Esta empresa foi utilizada no estudo de caso que está apresentado no item-6 deste artigo.

${ }^{13}$ MARTINS, Gilberto de Andrade.
} 
às demonstrações pró-forma divulgadas pela Andrade Gutierrez, na época de sua publicação. As entidades são formadas por 12 instituições financeiras, sendo 10 bancos privados e 02 públicos (BNDES e BDMG), uma empresa de rating, uma distribuidora de títulos e valores mobiliários, e pela ABAMEC Associação Brasileira dos Analistas do Mercado de Capitais. A coleta de dados foi feita através de um questionário enviado aos participantes por e-mail e devolvido por eles da mesma forma.

Vale ressaltar que, pelo fato de se ter utilizado o método não probabilístico, os resultados apresentados e os comentários se referem ao grupo de participantes escolhido como amostra. No entanto, deve-se destacar que dos 10 bancos privados que participaram da pesquisa, 08 estão entre os 20 maiores bancos por patrimônio, no ranking apresentado pela edição de 2002 de Melhores e Maiores, da Revista Exame. Assim, embora não se possa generalizar os resultados, entende-se que se trata de uma amostra com alto grau de qualidade.

A pesquisa de campo constatou que as demonstrações pró-forma são bem aceitas pelos analistas de mercado e de crédito que dela participaram. Quando perguntados: qual é a sua opinião sobre a divulgação das demonstrações contábeis consolidadas "pró-forma", como informação complementar às demonstrações publicadas de acordo com a Lei das S/A?, houve as seguintes respostas: $90 \%$ dos pesquisados responderam que esse tipo de publicação é importantíssimo, pois contribui para uma melhor análise das operações do grupo; $5 \%$ responderam que é importante, e os outros $5 \%$ responderam que serve como opção quando não se tem o consolidado de acordo com a lei.

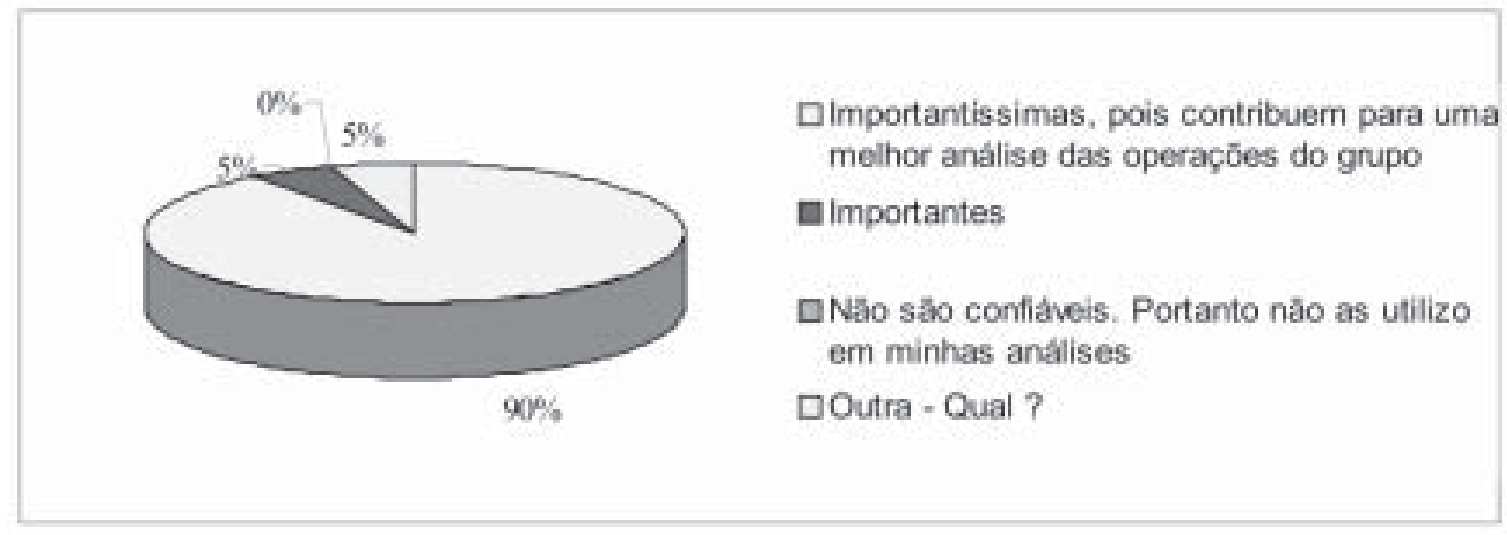

Gráfico 3 - Opinião sobre a publicação das demonstrações consolidadas pró-forma

Nota-se, então, que mesmo com as limitações mencionadas no item anterior (5.1.1), esta publicação é bem aceita pelos pesquisados. Pode-se inferir, pelos resultados da pesquisa, que eles recomendam sua publicação sempre que ocorrerem fatos relevantes que possam prejudicar a comparabilidade.

Portanto, se de um lado as demonstrações próforma não refletem os benefícios futuros que podem ser gerados pelos ativos consolidados, por outro, a falta dessas demonstrações pode comprometer a análise comparativa e a verificação da variação das contas de um período para outro.

Outra pergunta aberta foi feita para se saber a opinião dos participantes que analisaram as demonstrações consolidadas pró-forma da Andrade
Gutierrez, publicadas em 2001. O objetivo da pergunta foi identificar se essas demonstrações contribuíram para suas análises. Com isso, também foi possível saber, de forma dissertativa, o que pensam a respeito dessas demonstrações, uma vez que a pergunta anterior (gráfico-3) avalia a opinião de forma quantitativa. A seguir serão apresentados alguns comentários dos participantes da pesquisa, que transmitem aos leitores os benefícios gerados pela publicação do pró-forma da AG:

"Possibilitaram uma comparação com os demonstrativos de Resultados do Exercício de 1999 e 2000, que ficaria bastante prejudicada caso não fosse disponibilizado tal instrumento". (Adriano Salvetti Marchetti - Banco Bradesco) 
"Sem o balanço pró-forma não teríamos condição de analisar o novo perfil do grupo, analisar individualmente cada segmento em que o grupo atua $e$, mais ainda, qual o relacionamento entre eles (...) o balanço pró-forma era muito importante pois o grupo também estava iniciando operações em novos segmentos e ele possibilitou avaliar a performance tanto do grupo (decisão de diversificação) como também das novas empresas....". (Maria Regina Pitzer Martin - Citibank)

"Elas trazem maior clareza ao entendimento do desempenho econômico-financeiro do grupo em seus vários aspectos e segmentos. Este detalhamento permite uma visão mais clara da situação atual de cada atividade, permitindo projeções de desempenho e de nível de risco, individuais e consolidadas, mais confiáveis". (Paulo de Paula Abreu - Banco BBA Credinstalt)

"Os números da Telemar ${ }^{14}$ são tão significativos que seria impossível fazer uma comparação de desempenho entre os períodos se não fosse publicado o balanço pró-forma". (Milena Zaniboni Standard Poor's)

Nota-se, portanto, que na opinião desses participantes a publicação das demonstrações pró-forma foi imprescindível para a análise da empresa.

\section{ESTUDO DE CASO}

Yin ${ }^{15}$ cita que "o estudo de caso é preferido quando: o tipo de questão de pesquisa é da forma como e por quê?". Portanto, esta pesquisa está em conformidade com o mencionado, uma vez que procura apresentar como resgatar a comparabilidade das demonstrações contábeis quando acontecem fatos relevantes, como a aquisição de empresas ou reestruturações societárias.

\section{1 - A Escolha da Empresa}

Será utilizado, neste estudo, o caso da empresa Andrade Gutierrez S/A. Esta empresa é uma holding que tem participações em controladas que atuam em variados segmentos como: construção pesada, telecomunicações, concessões de serviços públicos e investimentos imobiliários. O carro-chefe deste grupo, até então, é a Construtora Andrade Gutierrez S/A, que atua no segmento de construção pesada no Brasil e em diversos países no exterior.

Foi escolhida essa empresa pelo fato de ela ter adquirido o controle conjunto de outra grande empresa nacional, a Telemar Participações S/A (controladora da Tele Norte Leste Participações S/ A, holding que controla 16 operadoras de telefonia fixa no país), e ter passado por uma reestruturação societária no período de 1999 a 2001, o que ocasionou a publicação das demonstrações consolidadas pró-forma referentes aos anos de 1999 e 2000, auxiliando na comparabilidade entre elas. Finalmente, entendemos que a apresentação de um caso real pode enriquecer muito este tipo de trabalho.

\section{2 - Coleta de Dados}

Os dados foram extraídos das demonstrações contábeis consolidadas da AG, dos anos de 1998, 1999 e 2000, da Telemar, de 1999, e da Tele Norte Leste, do ano de 1998. Portanto, foi utilizada a pesquisa documental para o desenvolvimento deste estudo de caso.

As demonstrações utilizadas foram publicadas em jornais de grande circulação e, portanto, são documentos de conhecimento público.

\section{3 - Descrição do Caso}

Em 29 de julho de 1998, o Governo Federal alienou $51,79 \%$ das ações com direito a voto da Tele Norte Leste. Essa alienação fez parte do Programa Nacional de Desestatização e aconteceu através de leilão de privatização de parte do Sistema Brasileiro de Telefonia Fixa.

A Andrade Gutierrez arrematou, em conjunto com outros investidores, o controle acionário da Tele Norte Leste - TNL, através do Consórcio denominado Telemar. Como resultado da participação neste Consórcio, a AG passou a deter $12,59 \%$

\footnotetext{
${ }^{14}$ Empresa cujo controle fora adquirido de forma compartilhada pela Andrade Gutierrez

${ }^{15}$ YIN, Robert K. Case Study Research: design and methods. Tradução e síntese: Prof. Ricardo Lopes Filho. Adaptação: Prof. Gilberto de Andrade Martins. Disponível no site: http://www.eac.fea.usp.br/metodologia/estudo caso.asp. Acessado em 10.04.2002.
} 
do capital votante da TNL. No entanto, 7,32\% seriam repassados para outros investidores e, por esse motivo, o registro do investimento, naquele ano, se deu da seguinte forma:

\begin{tabular}{l|c|c|c}
\hline Grupos do Ativo & $\begin{array}{c}\text { Valor Contábil do } \\
\text { Investimento - R\$ mil }\end{array}$ & $\begin{array}{c}\text { Participação no Capital } \\
\text { Votante - \% }\end{array}$ & $\begin{array}{c}\text { Participação no Capital } \\
\text { Total - \% }\end{array}$ \\
\hline Circulante & 485.323 & 7,32 & 2,72 \\
\hline Investimentos & 349.139 & 5,27 & 1,96 \\
\hline Total & 834.462 & 12,59 & 4,68 \\
\hline
\end{tabular}

Quadro 1 - Registro do Investimento na TNL em 1998

Em 31 de dezembro de 1998, data de fechamento das demonstrações, o modelo de gestão ainda não estava definido, e a holding Telemar Participações S/ A não se encontrava juridicamente formalizada. Portanto, o investimento ficou avaliado pelo método de custo, pois não havia sido definido se a AG teria ou não influência na sua administração.

Conforme consta na Nota Explicativa n. 6, que acompanha as demonstrações contábeis da Andrade Gutierrez do ano de 1999, em 30 de julho daquele ano os participantes do Consórcio subscreveram capital na holding Telemar, com os investimentos permanentes que possuíam na Tele Norte Leste. Assim, a Telemar passou a ter oficialmente o controle dos negócios dessa empresa, com participação de 51,79\% em seu capital votante, o qual representava $19,26 \%$ de seu capital total.
Em decorrência disso, a Andrade Gutierrez transferiu para os outros investidores o investimento registrado no ativo circulante e passou a ter $11,275 \%$ do capital votante (e total) da Telemar. Assim, a partir do ano de 1999, o investimento que era avaliado pelo método de custo passou a ser avaliado pelo método de equivalência patrimonial. Ficou estabelecido que o modelo de gestão seria o compartilhamento das deliberações societárias. Portanto, o investimento passou a ser consolidado nas demonstrações contábeis da AG.

O quadro, a seguir, mostra como esse investimento foi considerado nas demonstrações consolidadas da Andrade Gutierrez entre os anos de 1998 e 2000, uma vez que este período compreende o ano de aquisição do controle (1999), o ano anterior a ele (1998), e o posterior (2000).

\begin{tabular}{c|c|c|c}
\multirow{2}{*}{ Ano } & \multirow{2}{*}{ Balanço Patrimonial } & \multicolumn{2}{|c}{ Demonstração do Resultado do Exercício } \\
\cline { 3 - 4 } & Não consolidado & $\begin{array}{c}\text { Método de Avaliação } \\
\text { do Investimento }\end{array}$ & Consolidação \\
& $\begin{array}{c}\text { Consolidado } \\
\text { Patrimonial }\end{array}$ & Custo & Não consolidado \\
\hline 1998 & Consolidado & $\begin{array}{c}\text { Equivalência } \\
\text { de agosto a dezembro }\end{array}$ & Consolidado 05 meses: \\
\hline 2000 & & $\begin{array}{c}\text { Equivalência } \\
\text { Patrimonial }\end{array}$ & Consolidado 12 meses \\
& &
\end{tabular}

Quadro 2 - Forma de reconhecimento do investimento nos três períodos

\section{4 - A Publicação das Demonstrações Consolidadas Pró-forma da AG}

Nota-se claramente, no quadro-2, que a falta de uniformidade entre os três exercícios sociais ocasionou uma perda de comparabilidade das demonstrações consolidadas da AG nesse período, principalmente quanto ao resultado, uma vez que houve tratamento diferenciado nos três anos.

Em 1999, ano em que se consolidou pela primeira vez o investimento na Telemar, houve mui- tos questionamentos dos usuários, principalmente dos analistas financeiros, sobre a evolução dos valores das contas patrimoniais e de resultados. Vale destacar que os números da Telemar são muito representativos no consolidado da AG, e que, pelas demonstrações comparativas (1999 e 1998), não havia como determinar quanto da variação havia ocorrido em função da consolidação desse novo investimento e quanto em função das operações normais da controladora e das demais controladas constantes na consolidação. Houve, 
portanto, algumas dificuldades para a análise das demonstrações daquele ano.

No ano de 2000, a AG promoveu uma reestruturação societária separando suas áreas de negócios, o que ocasionou a constituição de uma holding não operacional e quatro sub holdings. Foram efetuadas diversas transferências de investimentos para estas novas holdings. Essa questão, aliada ao fato de que nesse ano o resultado consolidado abrangeu todo o exercício social da Telemar, levou a Andrade Gutierrez a elaborar as demonstrações consolidadas pró-forma do ano de 2000 , publicando também o pró-forma do ano de 1999 para fins comparativos, como se todos esses fatos já tivessem ocorrido naquele ano, tendo inclusive considerado 12 meses de resultado da Telemar.

Isso possibilitou aos usuários efetuar as análises comparativas e inferências sobre as tendências futuras desse grupo empresarial. Conforme apresentado no item-5.1.2, na opinião dos profissionais do mercado financeiro e de capitais, que participaram da pesquisa de campo, a publicação das demonstrações contábeis pró-forma da Andrade Gutierrez contribuiu muito para suas análises. Vale lembrar que alguns dos profissionais pesquisados enfatizaram que seria impossível efetuar as análises se não houvesse a publicação do pró-forma.

\section{5 - Apresentação dos Dados das Demonstrações Consolidadas Legais e Pró-forma}

Na seqüência, são apresentados alguns dados dos balanços patrimoniais consolidados e das demonstrações de resultados consolidadas da Andrade Gutierrez dos exercícios sociais de 1998, 1999 e 2000. São apresentados os dados de acordo com as demonstrações legais, ou seja, elaboradas de acordo com a legislação brasileira, e os dados das demonstrações pró-forma, para que se possa avaliar se realmente essas demonstrações oferecem melhores condições de análise quando ocorrem fatos relevantes como os descritos nesta pesquisa.

Conforme consta na Nota Explicativa n. -2 , que acompanha as demonstrações contábeis consolidadas do ano de 2000, as demonstrações pró-forma foram elaboradas observando-se as práticas contábeis contidas na Lei $n .-06.404 / 76$. Foram efetuados os ajustes necessários a uma apresentação comparativa, como se os eventos (aquisições societárias e reestruturações) tivessem ocorrido nos anos anteriores.

Não se pretende, neste estudo, fazer uma análise da performance econômica, financeira ou operacional da empresa. Aqui, como já destacado no item 5.1.1 (Limitações das demonstrações consolidadas pró-forma), vale ressaltar que os valores pró-forma não estão sob a gestão e controle dos atuais controladores e os dados que serão apresentados têm como único objetivo comparar as informações contidas nas demonstrações legais com as pró-forma. Serão apresentados os principais itens, em que existem grandes diferenças entre os dois tipos de demonstrações.

As informações extraídas das demonstrações elaboradas com base na legislação societária serão aqui chamadas de legal, e as demais de próforma. Todos os dados expressos em valores estão apresentados nos quadros em milhões de reais.

\subsection{1- Comparação das Contas Patrimoniais}

\begin{tabular}{c|c|c|c}
\hline Ano / Tipo & $\mathbf{2 0 0 0}$ & $\mathbf{1 9 9 9}$ & $\mathbf{1 9 9 8}$ \\
Legal & 6.420 & $5.834^{*}$ & $3.500^{*}$ \\
\hline Pró-forma & 6.420 & 6.056 & 5.209
\end{tabular}

Quadro 3 - Comparação do Ativo Total

Pelas demonstrações legais, de 1998 para 1999, o ativo variou em $\mathrm{R} \$ 2.334$ milhões, apresentando uma evolução de $67 \%$. No ano de 1999, houve a aquisição do controle conjunto da Telemar. Assim, ficaria difícil para o leitor mensurar quanto desse aumento foi gerado pela consolidação da Telemar, já que foi o primeiro ano de consolidação desta controlada, e quanto pelas demais transações do período. Pelos dados do pró-forma, o aumento dos ativos seria de apenas $16 \%$, comparando-se aos 67\%. Do ano de 1999 para o de 2000 não houve variação relevante, mesmo no consolidado legal. Isso ocorreu porque o balanço patrimonial é consolidado independentemente da data em que houve a aquisição.

"Em 1999 e 1998 foram excluídos os Direitos de Outorga (ativo imobilizado) e as dívidas correspondentes (passivo), com a finalidade de manter a uniformidade, uma vez que a empresa retirou esse item do seu imobilizado no ano de 2000 em função de mudança de procedimentos. Nas demonstrações pró-forma esses itens já estão excluídos. 
Portanto, nos dois períodos constam as parcelas dos itens patrimoniais que cabem à controladora.

\begin{tabular}{c|c|c|c|}
\hline Ano / Tipo & $\mathbf{2 0 0 0}$ & $\mathbf{1 9 9 9}$ & $\mathbf{1 9 9 8}$ \\
Legal & 2.108 & $1.720^{*}$ & $340^{*}$ \\
Pró-forma & 2.108 & 1.952 & 1.864 \\
\hline
\end{tabular}

Quadro 4 - Comparação do Imobilizado

Nesse item, a variação nas demonstrações legais também foi bastante expressiva, enquanto no pró-forma os valores variaram pouco de um período para outro. Isso pode significar, dentre outras coisas, que não houve grandes aquisições. Essa informação ficaria distorcida se analisada simplesmente pelos dados legais, uma vez que apresenta variação de $R \$ 1.380$ milhões (406\%), de 1998 para 1999.

\begin{tabular}{c|c|c|c|}
\hline Ano / Tipo & 2000 & 1999 & 1998 \\
Legal & 2.528 & $1.800^{*}$ & $996^{*}$ \\
Pró-forma & 2.528 & 2.055 & 1.619 \\
\hline
\end{tabular}

Quadro 5 - Comparação do Passivo Exigível

Nota-se, pela evolução dos valores do pró-forma, que realmente o endividamento aumentou ao longo dos três períodos, em torno de $\mathrm{R} \$ 450$ milhões/ano. No entanto, analisando-se o balanço legal verifica-se que de 1998 para 1999 houve um aumento de $\mathrm{R} \$ 804$ milhões. Sem o pró-forma, ficaria difícil estimar se essa variação teria ocorrido em função de novas dívidas ou em função da consolidação da Telemar.
Participação do capital de terceiros em relação ao patrimônio líquido:

\begin{tabular}{|c|c|c|}
\hline \multicolumn{3}{|l|}{ Dados Legais: } \\
\hline Fórmula & em 1999 & em 1998 \\
\hline Passivo Exigível & $1.800=0,69$ & $\underline{996}=0,40$ \\
\hline Patrimônio Líquido & 2.626 & 2.502 \\
\hline \multicolumn{3}{|l|}{ Dados Pró-forma: } \\
\hline Fórmula & em 1999 & em 1998 \\
\hline Passivo Exigível & $\underline{2.055}=0,78$ & $\underline{1.619}=0,67$ \\
\hline Patrimônio Líquido & 2.650 & 2.433 \\
\hline
\end{tabular}

Esse indicador representa o montante de capital de terceiros que a empresa está utilizando em relação ao capital próprio. Pelos dados legais, esse indicador apresenta grande distorção: tem-se a impressão de que, de 1998 para 1999, a empresa aumentou em mais de 70\% a participação de capital de terceiros em relação ao próprio, pois saiu de 0,40 para 0,69 . No entanto, essa alta evolução ocorreu em função da consolidação da Telemar. Pelo pró-forma, percebe-se que essa evolução foi de apenas $16 \%$ (de 0,67 para 0,78 ) no período.

\subsection{2- Comparação das Contas de Resultado}

$\mathrm{Na}$ demonstração do resultado consolidada referente a 1998, publicada de acordo com a lei, não constam os valores da Telemar; na de 1999 constam os valores de agosto a dezembro, enquanto na de 2000 consta o período completo. O quadro, a seguir, apresenta alguns itens para comparação:

\begin{tabular}{|c|c|c|c|c|c|c|c|c|c|}
\hline & \multirow[b]{3}{*}{$\begin{array}{c}2000 \\
\text { R\$ milhões }\end{array}$} & \multicolumn{4}{|c|}{1999} & \multicolumn{4}{|c|}{1998} \\
\hline & & \multirow[b]{2}{*}{$\begin{array}{l}\text { Pró-Forma } \\
\text { R\$ milhões }\end{array}$} & \multirow[b]{2}{*}{$\begin{array}{c}\text { Legal } \\
\text { R\$ milhões }\end{array}$} & \multicolumn{2}{|c|}{ Variação \% } & \multirow[b]{2}{*}{$\begin{array}{l}\text { Pró-Forma } \\
\text { R\$ milhões }\end{array}$} & \multirow[b]{2}{*}{$\begin{array}{c}\text { Legal } \\
\text { R\$ milhões }\end{array}$} & \multicolumn{2}{|c|}{ Variação \% } \\
\hline & & & & $\begin{array}{l}2000 / \\
99 \mathrm{PF}\end{array}$ & $\begin{array}{c}2000 / \\
99 \text { Legal }\end{array}$ & & & $\begin{array}{l}2000 / \\
98 \mathrm{PF}\end{array}$ & $\begin{array}{c}2000 / \\
98 \text { Legal }\end{array}$ \\
\hline Receita Operacional Líquida & 2.326 & 1.745 & 1.242 & $33 \%$ & $87 \%$ & 1.957 & 1.374 & $19 \%$ & $70 \%$ \\
\hline Custo dos Serviços Prestados & $(1.642)$ & $(1.291)$ & $(996)$ & $27 \%$ & $65 \%$ & $(1.500)$ & $(1.160)$ & $10 \%$ & $42 \%$ \\
\hline Resultado Operacional Bruto & 684 & 454 & 246 & $50 \%$ & $178 \%$ & 457.000 & 214 & $50 \%$ & $220 \%$ \\
\hline Desp. Gerais, Adm. e Vendas & $(447)$ & $(406)$ & (304) & $10 \%$ & $47 \%$ & (393) & $(230)$ & $14 \%$ & $94 \%$ \\
\hline Outras Receitas (Desp.) Ope. & $(39)$ & 1 & 1 & $(42)$ & 19 & & & & \\
\hline$E B I T$ & 198 & 49 & $(57)$ & $30 \%$ & $447 \%$ & 22 & 3 & $800 \%$ & $6.500 \%$ \\
\hline Depreciação e Amortização & 440 & 466 & 202 & $-6 \%$ & $118 \%$ & 213 & 40 & $107 \%$ & $1.000 \%$ \\
\hline EBITDA & 638 & 515 & 145 & $24 \%$ & $340 \%$ & 235 & 43 & $172 \%$ & $1.384 \%$ \\
\hline
\end{tabular}

Quadro 6 - Comparativo Contas de Resultado - Consolidado Pró-Forma x Legal 
Observa-se que, no consolidado legal, algumas variações de 1998 para 1999 não foram tão expressivas quanto em 2000. Isso se deve ao fato de que, apesar de constarem cinco meses das contas da Telemar em 1999, e de não constar nada no ano anterior, as operações da controladora, em 1999, tiveram uma grande redução. Por isso, os valores da Telemar, naquele ano, acabaram por compensar a queda dos números da controladora, deixando o consolidado razoavelmente equilibrado de um período para outro.

No consolidado pró-forma, a variação também não foi muito relevante nesses dois anos, o que demonstra certa uniformidade nas operações, uma vez que consta o período integral da Telemar em ambos e, embora tenha ocorrido uma queda nas transações da controladora em 1999, a Telemar obteve naquele ano uma movimentação bem maior que em 1998, mantendo, portanto, um razoável equilíbrio entre os dois períodos.

Por essas razões, nas comparações, a seguir, serão enfatizadas, principalmente, as variações de 2000 em relação a 1999.

Receita Operacional Líquida: no consolidado legal, de 1999 para 2000, houve um aumento de $\mathrm{R} \$$ 1.084 milhões. Analisando-se somente por essa demonstração, poder-se-ia concluir que esse grupo empresarial aumentou suas vendas/serviços em $87 \%$, de um ano para outro. Portanto, numa análise de tendências futuras, projetando-se para os próximos períodos um aumento semelhante a esse, chegar-se-ia a conclusões errôneas, pois esse fato se deu, principalmente, em função da diferença de períodos consolidados da Telemar: em 2000 os doze meses, enquanto no ano anterior apenas cinco. Verificando-se o consolidado pró-forma, nota-se que a evolução em 2000 foi de 33\% em relação ao ano anterior, e de 19\% em relação a 1998, oferecendo, assim, uma tendência mais coerente com a realidade para os períodos seguintes, já que no pró-forma a receita da Telemar está inserida nesses três anos.

Resultado Operacional Bruto: verificando-se pelo pró-forma, observa-se que houve um grande aumento desse resultado em 2000, chegando a uma variação aproximada de $50 \%$ em relação ao ano anterior. Isso ocorreu em função do valor absoluto das receitas líquidas ter aumentado mais que o valor dos custos. No entanto, essa variação foi bem menor que a apresentada pelo consolidado legal, que mostra um aumento nesse resultado de cerca de 178\% em relação a 1999.

Portanto, se para analisar tendências futuras esse aumento de $50 \%$, apresentado no pró-forma, deve ser verificado com certa cautela, o de $178 \%$ apresentado no consolidado legal deve ser praticamente descartado nessa análise, pois tem-se observado que, se fatos extraordinários não ocorrerem, não é comum uma empresa aumentar seu resultado bruto em patamares tão altos de um período para outro.

Despesas Gerais, Administrativas e com Vendas: nota-se que no consolidado legal essas despesas aumentaram $47 \%$, no ano de 2000 , em relação ao anterior, e $94 \%$ em relação a 1998. Sem a publicação das informações pró-forma seria difícil para o usuário inferir sobre as tendências para os próximos períodos, pois as variações apresentadas no consolidado legal não refletem a efetiva evolução, enquanto no pró-forma a variação foi bem mais uniforme e coerente de um período para outro. De 1998 para 1999 houve pequena variação e, deste ano para 2000 , aumentou $10 \%$. O gráfico-4, a seguir, além de apresentar a evolução dos valores, mostra também as linhas de tendências que ilustram o mencionado.

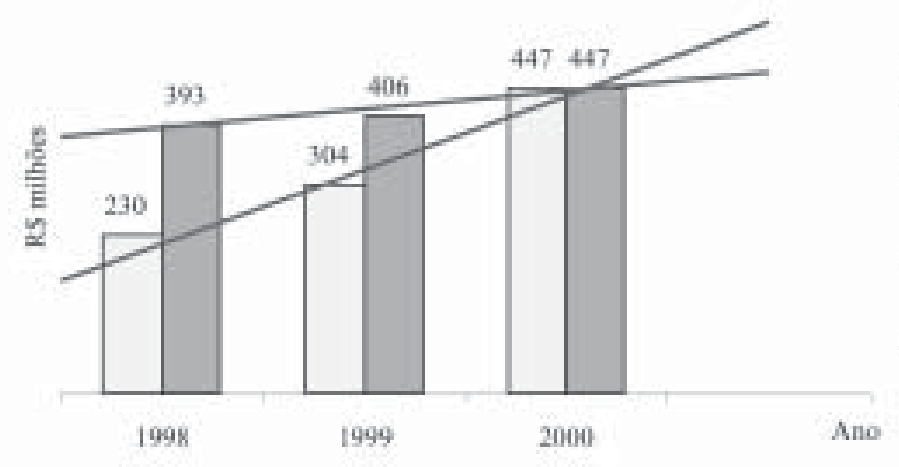

$\square$ Conselidade Legal

Consolidado Pró-Fome

- Tendência Consolidado Legal

— Tendência Consolidado Pró-Forma

Gráfico-4 - Comparativos das Despesas Gerais, Administrativas e com Vendas 
EBITDA: verificando-se a evolução desse medidor, de 1999 para 2000, observa-se que pela consolidação legal houve um crescimento de $340 \%$, enquanto pelo pró-forma o aumento foi de apenas $24 \%$. Novamente destaca-se que seria muito difícil determinar tendências futuras sem a apresentação do pró-forma, pois a evolução de $340 \%$ se deu em função da diferença de períodos consolidados da Telemar.

\section{6- Considerações finais sobre o estudo de caso}

Nota-se, pelo estudo desse caso real, que a publicação das demonstrações consolidadas pró-forma contribuiu muito para a análise comparativa dos três períodos contábeis apresentados. Esse fato foi reconhecido, inclusive, pelos analistas que participaram da pesquisa de campo, cujas opiniões já foram destacadas.

As demonstrações legais apresentaram variações que praticamente impossibilitariam, ou dificultariam em muito, as análises de tendências desse grupo empresarial, enquanto pelo pró-forma foi possível fazer algumas inferências.

\section{CONCLUSÕES}

Este estudo enfatizou a importância da consolidação das demonstrações contábeis, principalmente no exercício social em que ocorre a aquisição do controle de empresas, pois, ao se inserir uma nova sociedade no consolidado, pode haver uma perda de comparabilidade com o ano anterior e com o posterior à sua aquisição.

A comparabilidade entre as demonstrações de um exercício social para outro é um fator importante, uma vez que através dela é possível inferir sobre as tendências futuras. Isso não significa que o ocorrido no presente ou no passado vai se repetir no futuro, e sim que, se fatos extraordinários e/ou relevantes não ocorrerem, as possibilidades de uma continuidade razoavelmente uniforme das operações são grandes.
A elaboração das demonstrações pró-forma é uma das maneiras de se resgatar essa comparabilidade, uma vez que são feitos ajustes extra-contábeis, única e exclusivamente para fins de comparação, com a finalidade de refletir, nas demonstrações anteriores, fatos ocorridos no presente que estejam prejudicando a análise comparativa.

O estudo de caso apresentado mostrou que algumas análises poderiam ficar prejudicadas se não houvesse a publicação das demonstrações pró-forma. Este fato foi confirmado pelos participantes da pesquisa de campo que chegaram a declarar que, na opinião deles, seria impossível a análise daquela empresa (AG) sem a publicação das demonstrações pró-forma, uma vez que a incorporação de uma nova sociedade nas demonstrações consolidadas alterou, de maneira substancial, os valores daquele grupo empresarial de um período para outro. Pelo exposto neste estudo, pode-se verificar que as demonstrações consolidadas pró-forma, embora tenham suas limitações, principalmente no que diz respeito aos benefícios presentes ou futuros gerados pelos ativos, são consideradas pelos participantes da pesquisa como ferramentas úteis e essenciais para auxiliar os usuários, principalmente investidores e credores, em sua tomada de decisões.

Outro destaque importante deste estudo foi a pesquisa realizada junto a profissionais de mercado e em que se pode constatar a grande importância dada por esses profissionais às demonstrações pró-forma. Embora não se possa generalizar, por ter sido adotado o método não probabilístico, trata-se da opinião de profissionais que atuam em importantes instituições do mercado financeiro e de capitais, e que analisam diariamente demonstrações contábeis de empresas dos mais variados setores.

O trabalho demonstrou, também, que embora a consolidação seja normatizada, sua elaboração e publicação deve ir além do exigido através de normas e lei, pois isso poderá aumentar a capacidade informativa dessas demonstrações contábeis. 


\section{REFERÊNCIAS BIBLIOGRÁFICAS}

ACCOUNTING RESEARCH BULLETIN. ARB n. 51 Consolidated Financial Statements.

BANCO CENTRAL DO BRASIL. Circular n. 0179 , de 11 de maio de1972. Estabelece as Normas Gerais de Auditoria.

BRASIL. Lei n.ํ 6.404, de 15 de junho de 1976. Dispõe sobre as sociedades por ações.

COMISSÃO DE VALORES MOBILIÁRIOS - CVM. Instrução n.? 247 , de 27 de março de 1996. Dispõe sobre a avaliação de investimentos em sociedades coligadas e ção das demonstrações contábeis consolidadas.

DELANEY, Patrick R. et al. GAAP 2001 - Interpretation and Application. New York - EUA. John Wiley \& Sons, Inc. 2001.

FASB - Financial Accounting Standards Board. Original Pronouncements. New York: John Witey \& Sons. 1998, vol. I e II. Subsidiaries.

FAS-94 - Consolidation of All Majority Owned

FIPECAFI - USP. Manual de contabilidade das sociedades por ações. 5 ed. São Paulo: Atlas, 2000.

GODOY, Carlos R., SANTOS, Ariovaldo. Push-Down Accounting. Revista Conselho Regional de Contabilidade - CRC de São Paulo. São Paulo, v. 15 p. 23-39, março 2001.

IASC - INTERNATIONAL ACCOUNTING STANDARDS COMMITTEE. IAS-5 - Informações a serem divulgadas nas Demonstrações Contábeis, revisado em 1994.

IAS-25 - Contabilização dos Investimentos reformulado em 1994.

IAS-27 - Demonstrações Contábeis Consolidadas e Contabilização dos Investimentos em Subsidiárias reformulado em 1994.
IAS-28 - Contabilização de Investimentos em Empresas Associadas - reformulado em 1994.

KPMG Corporate Finance. Fusões \& Aquisições. Publicação disponível no site: http://www.kpmg.com.br - publicações. Acesso: Abril de 2002.

MACHADO, Itamar Miranda. Consolidação das demonstrações contábeis quando ocorre aquisição do controle de empresas durante o exercício social.2002. Dissertação (Mestrado em Controladoria e Contabilidade) - Faculdade de Economia, Administração e Contabilidade, Universidade de São Paulo, São Paulo.

MARTINS, Eliseu. Iniciação à Equivalência Patrimonial Considerando Algumas Regras Novas da CVM. São Paulo: IOB Informações Objetivas -TC-38 e 39/97, 1997.

Quais Investimentos Devem Ser Avaliados Pela Equivalência Patrimonial?. São Paulo: IOB - Informações Objetivas - TC- 34 e 35/97, 1997.

MARTINS, Gilberto de Andrade. Manual para Elaboração de Monografias e Dissertações. 2 ed. São Paulo: Atlas, 2000.

MELLO, Carlos E.S.S. Análise de Balanço da Empresa Sob o Ponto de Vista Financeiro. Lisboa: Portugáli. 1953.

MYER, John Nicholas. Análise das Demonstrações Financeiras. São Paulo: Traduzido por Danilo Ameixeiro Nogueira, Atlas. 1976.

STANDERSKI, Wlademiro. Consolidação de Balanços de Empresas Nacionais e Multinacionais. São Paulo: Livraria Pioneira, 1976.

YIN, Robert K. Case Study Research: design and methods. Tradução e síntese: Prof. Ricardo Lopes Filho. Adaptação: Prof. Gilberto de Andrade Martins. Disponível em: <http://www.eac.fea.usp.br/ metodologia/estudo caso.asp>. Acesso em: 10 abr. 2002.

\section{NOTA:}

Endereço dos autores:

ITAMAR MIRANDA MACHADO

Rua Paraíba, 330 - 4ํandar - Funcionário

Belo Horizonte - MG

30130-140

ARIOVALDO DOS SANTOS

Av. Prof. Luciano Gualberto, 908 - prédio 3

Cidade Universitária - Butantã

São Paulo - SP

05508-900 